\title{
Mental Health and Psycho-Social-Spiritual Support for Muslim Populations in Emergency Settings
}

Saleem Khaldoon Al-Nuaimi, MD, MSc, FRCPC

University of Alberta, 116 St. \& 85 Ave., Edmonton, AB T6G 2R3, Canada

sa@ualberta.ca

\section{Walid Qoronfleh ${ }^{1}, P h D, M B A$}

Research \& Policy Department, World Innovation Summit for Health (WISH), Qatar Foundation, P.O. Box 5825, Doha, Qatar wqoronfleh@qf.org.qa

There are 50 Muslim majority countries in our world today, with a total population of approximately 1.8 billion people (Lipka \& Hacket, 2017). About 91\% of the total population in the Middle East-North Africa (MENA) identify as Muslim, but this makes up only $\sim 20 \%$ of the total Muslim population (Pew Research Center, 2011). Most Muslims live in Asian-Pacific countries such as Indonesia, Pakistan, India, Bangladesh Iran and Turkey. Muslims account for $31 \%$ of the population in South Asia (Pew Research Center, 2011), 30\% in Sub-Sahara Africa (Pew Research Center, 2013), 6\% in Europe, and 1\% in the Americas (Pew Research Center, 2013). Therefore, Muslims not only make up a sizeable number of the total human population, but they are also a geographically diverse group.

Many Muslim majority countries are affected by significant political, social, economic and security challenges resulting in various forms of human suffering and devastation. The unprecedented displacement of persons is one such form of human devastation. There are over 25 million refugees worldwide with the majority coming from Muslim-majority countries. Furthermore, out of the world's top 10 refugee host countries, the majority are Muslim-majority host countries (UNHCR, 2018).

1. Corresponding author: wqoronfleh@qf.org.qa 
There are many community-based psychosocial support training kits as well as other various mental health resources, guidelines and manuals available to agencies and organizations working with populations in emergency settings. However, to our knowledge, there is no comprehensive resource providing specific guidance and understanding of the psycho-social needs of Muslim populations through the lens of their unique religious-spiritual paradigm.

One may question why the religious-spiritual paradigm is an important one to explore and how that relates to mental health and psycho-social wellbeing for populations afflicted by crisis events.

Overall, religion tends to play a positive influence in the lives of people (Koenig, 2004). Many studies have shown that greater religiosity or spirituality is associated with lower rates of depression (Cotton et al., 2006), may help individuals better cope with life stressors (Bonelli et al., 2012), is associated with less symptoms of post-traumatic stress (Arevalo et al., 2008), and is a protective factor in reducing risk of suicide (Cotton et al., 2006). It is not unreasonable to generalize such findings to Muslims as well. A study reported that depressed Afghan refugees with a higher degree of religiosity were less vulnerable to suicidal planning or attempts (Jahangir et al., 1998).

In addition to the benefits that religion-spirituality may play in the life of an individual, there is also evidence suggesting that increased religiosity in a community can buffer them against the psychological distress following a natural disaster (Stratta et al., 2013). A more specific example can be seen in the religious significance of burial ceremonies. Islam places great importance in the rituals and rights of a proper burial for the deceased. Cultures that hold final ceremonies for their dead experience far fewer signs of prolonged grief, such as suicidal behavior, troubled dreams, as well as physical and mental illness (Rosenblatt et al., 1976).

It is equally important to note that certain aspects of religion may also pose significant challenges for individuals and communities, typically due to misunderstanding, ignorance or other factors. For example, focusing on God from a punitive dimension can result in significant religious-spiritual struggles for individuals (Silton et al., 2014). Therefore, the role of religious-spiritual leaders will play a vital role in addressing these struggles and, in turn, help improve mental wellbeing.

There is growing appreciation and incorporation of religiously informed psycho-social support for communities afflicted with an emergency event. The Lutheran World Federation (LFW) and Islamic Relief Worldwide (IRW) published a manual entitled "A Faith-Sensitive Approach in Humanitarian Response: Guidance on Mental Health and Psychosocial Programming" (LWF and IRW, 2018). The goal of this manual is to assist both secular and faithbased organizations in their humanitarian work across all sectors, with a focus on mental health and psychos-social support programming. The publication of this manual is a testament to the acceptance of religion and faith into main- 
stream, secular humanitarian programming of international agencies. To quote the LEW and IRW press release: "The manual, entitled "A Faith-Sensitive Approach in Humanitarian Response: Guidance on Mental Health and Psychosocial Programming," is designed to assist both secular and faith-based organisations in their work with refugees and host communities."

However, we propose to take this to a deeper level. We envision a project that looks at events and crises from an Islamic Perspective to develop an evidence-based, culturally and spiritually sensitive psycho-social training manual to guide trainers on working with Muslim populations afflicted by an emergency event. An immediate example that illustrates necessity of preparedness the potential spread of Coronavirus (Covid-19) amongst refugees in their sub-optimal camps and the mental stress or anguish it generates to individuals and their families.

The training manual is to be operationalized as an adjunct to scientifically established international training manuals, such as the Mental Health PsychoSocial Support training manuals developed by the World Health Organization and the Community-Based Psychosocial Support Training Kit developed by the International Federation Reference Centre for Psychosocial Support. While the LFW and IRW publication focuses on the overarching faith-based approach as a framework, we are more interested into the precise, translational details of such an approach specific to Muslims.

The elements of this manual are the following:

1. Understanding Crises Events

- What is an emergency setting (crisis/disaster) from an Islamic perspective?

- What is the understanding and approach to suffering as a Muslim?

- Exploring the virtue of Sabr (Patience)

- Exploring Qatha' \& Qadr (Fate, Destiny and Free-Will) and challenging misconceptions in an emergency setting

2. Stress and Coping Strategies

a. Religious coping strategies for the Muslim individual

- Prayer (Salat)

- Remembrance of God (Thikr)

- Supplication (Duáa)

- Quran recitation

- Repentance (Tawbah)

b. Religious coping strategies for the Muslim community

- Spiritual guidance from local religious leaders

- Support from relatives

- Support from friends

- Support from the greater Muslim community 
3. Loss and Grief

a. The Islamic perspective on loss \& grief

b. The Islamic burial, Janaza prayer \& condolences

4. The Role of Religious Counsellors and Elders of the Community a. Incorporating the elders and religious counsellors into psychosocial support

5. Self-Care: Islamic Perspective and Strategies

We firmly believe it is critical to aim to develop a validated, evidence-based, and religiously informed training resource providing specific guidance and understanding to the psycho-social needs of Muslim populations afflicted by an emergency event. There are many resources available that are culturally sensitive and faith informed. However, they lack the specific details and comprehensive understanding that is required to adequately incorporate and translate religiously informed training into the delivery of mental health and psycho-social support to Muslim communities in a concrete way to the general population and in particular in an emergency and/or conflict setting.

\section{DECLARATIONS}

\section{ETHICS APPROVAL AND CONSENT TO PARTICIPATE}

None Applicable.

\section{CONSENT FOR PUBLICATION}

None Applicable.

\section{AVAILABILITY OF DATA AND MATERIALS}

All data generated or analyzed during this study are included in this published article.

\section{COMPETING / CONFLICTS OF INTEREST}

None. The author declares that there are no conflicts of / or competing interests. 


\section{FUNDING}

No supported funds were received.

\section{AUTHORS' CONTRIBUTIONS}

Authors conceived, designed and implemented conceptual work, framework, writing and critical editing. Authors read and approved the final manuscript.

\section{ACKNOWLEDGEMENTS}

The author wants to thank his institution for their continued support.

\section{References}

Arevalo S, Prado G, Amaro H. Spirituality, sense of coherence, and coping responses in women receiving treatment for alcohol and drug addiction. Eval Program Plann 2008; 31:113-123. https://doi.org/10.1016/j.evalprogplan.2007.05.009

Bonelli R, Dew RE, Koenig HG, et al. Religious and spiritual factors in depression: review and integration of the research. Depress Res Treat 2012; 2012:962860. doi: 10.1155/2012/962860. Epub 2012 Aug 15. https://doi.org/10.1155/2012/962860

Cotton S, Zebracki K, Rosenthal S, et al. Religion/spirituality and adolescent health outcomes: a review. J Adolesc Health 2006; 38:472-480. https://doi.org/10.1016/j. jadohealth.2005.10.005

Jahangir, F., Rehman, H., \& Jan, T. (1998). Degree of religiosity and vulnerability to suicidal attempt/plans in depressive patients among Afghan refugees. International Journal for the Psychology of Religion, 8(4), 265-269. https://doi.org/10.1207/ s15327582ijpr0804_6

Koenig HG. Spirituality, wellness, and quality of life. Sex Reprod Menopause 2004; 2:76-82. https://doi.org/10.1016/j.sram.2004.04.004

The Lutheran World Federation and Islamic Relief Worldwide (2018). A faith-sensitive approach in humanitarian response: Guidance on mental health and psychosocial programming. LWF and IRW: Geneva and Birmingham.

Michael Lipka \& Conrad Hackett (6 April 2017). "Why Muslims are the world's fastestgrowing religious group”. Pew Research Center.

"Region: Americas". The Future of the Global Muslim Population. Pew Research Center. Archived from the original on 7 April 2013.

"Region: Europe". The Future of the Global Muslim Population. Pew Research Center. Archived from the original on 7 April 2013.

"Region: Middle East-North Africa". The Future of the Global Muslim Population. Pew Research Center. 27 January 2011.

“Region: Asia-Pacific”. Pew Research Center’s Religion \& Public Life Project. 27 January 2011.

"Region: Sub-Saharan Africa". The Future of the Global Muslim Population. Pew Research Center. Archived from the original on 9 March 2013. 
Rosenblatt, P. C., Walsh, H. P., \& Jackson, D. A. (1976). Grief and mourning in crosscultural perspective. New Haven, CT: HRAF Press

Stratta P, Capanna C, Riccardi I, et al. Spirituality and religiosity in the aftermath of a natural catastrophe in Italy. J Relig Health 2013; 52:1029-1037. https://doi. org/10.1007/s10943-012-9591-Z

Silton NR, Flannelly KJ, Galek K, Ellison CG. Beliefs about God and mental health among American adults. J Relig Health. 2014 Oct;53(5):1285-96. https://doi. org/10.1007/s10943-013-9712-3

Thompson R, Kapila M. Healthcare in Conflict Settings: Leaving No One Behind. Doha, Qatar: World Innovation Summit for Health, 2018

UNHCR Global Trends Forced Displacement 2018. https://www.unhcr.org/globaltrends2018/ 